\title{
Progressive improvement of myocardial perfusion after off- pump revascularization with bilateral internal thoracic arteries: Comparison of early versus 1-year postoperative myocardial single photon emission computed tomography
}

Kwang Ree Cho, MD, PhD, ${ }^{a}$ Ho Young Hwang, MD, ${ }^{a}$ Won Jun Kang, MD, PhD, ${ }^{\text {b }}$ Dong Soo Lee, MD, PhD, ${ }^{\text {b }}$ and Ki-Bong Kim, MD, PhD ${ }^{a}$

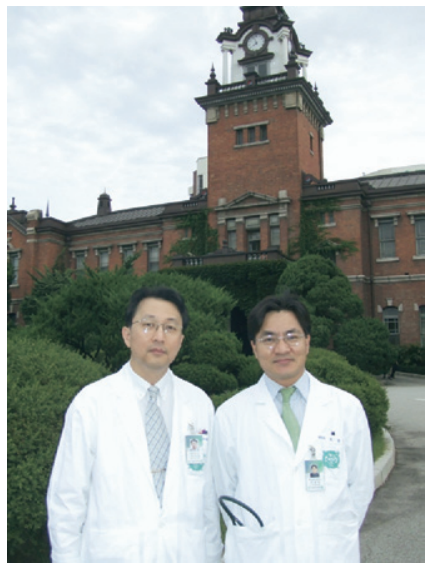

Drs Kim and Cho (left to right)
From the Departments of Thoracic and Cardiovascular Surgery ${ }^{\mathrm{a}}$ and Nuclear Medicine, ${ }^{\mathrm{b}}$ Seoul National University Hospital, Seoul, Korea.

Received for publication May 23, 2006; revisions received Aug 3, 2006; accepted for publication Sept 6, 2006

Address for reprints: Ki-Bong Kim, MD, $\mathrm{PhD}$, Department of Thoracic and Cardiovascular Surgery, Seoul National University Hospital, 28, Yeongeon-dong, Jongnogu, Seoul 110-744, Korea (E-mail: kimkb@snu.ac.kr).

J Thorac Cardiovasc Surg 2007;133:52-7

$0022-5223 / \$ 32.00$

Copyright (C) 2007 by The American Association for Thoracic Surgery

doi:10.1016/j.jtcvs.2006.09.014
Objective: We evaluated the time course of myocardial perfusion improvement after off-pump revascularization.

Methods: Seventy-six patients who underwent off-pump coronary bypass with bilateral internal thoracic arteries for revascularization of the left coronary territory were studied. Myocardial single photon emission computed tomography was performed preoperatively and at 3 months and 1 year postoperatively. Myocardial perfusion was quantified with automatic software, and the left coronary territory was divided into 16 segments. As an indicator of the ischemic myocardium, the reversibility score was defined as a measure of rest minus stress perfusion values. A total of 403 segments that showed a reversibility score of 7 or greater preoperatively were included.

Results: The reversibility score was improved significantly at 3 months postoperatively $(P<.001)$ and further improved 1 year after the operation $(P<.001)$. When the patients were divided into 2 groups based on the type of bilateral internal thoracic arteries used (group Y: Y-composite graft, $\mathrm{n}=39$; group I: bilateral in situ grafts, $\mathrm{n}=37)$, the reversibility score was improved significantly 3 months after the operation $(P<.001)$ and further improved 1 year after the operation $(P<.001)$ in both groups. There were no significant differences in the reversibility scores between groups $\mathrm{Y}$ and $\mathrm{I}$ at postoperative month $3(P=.463)$. The scores approached zero in both groups at 1 year postoperatively (group $\mathrm{Y},-1.7 \% \pm 7.9 \%$; group I, $1.3 \% \pm 7.2 \%)$.

Conclusions: The myocardial reversibility score improved greatly during the first 3 months after the operation and further improved until 1 year postoperatively. Perfusion improvement was similar between the Y-composite and bilateral in situ internal thoracic artery grafts in terms of the reversibility score.

$\mathrm{T}$ he effect of coronary artery bypass grafting on ischemic myocardium has been demonstrated as a progressive improvement of myocardial blood flow and function after successful revascularization. ${ }^{1-3}$ The use of 2 internal thoracic arteries (ITAs) instead of 1 has demonstrated advantages, such as enhanced long-term survival rates and greater freedom from reinterventions in surgical revascularization for multivessel coronary artery disease. ${ }^{4,5}$ Although use of a composite graft has indicated an increased coronary flow reserve through the graft when using the bilateral ITAs, ${ }^{6,7}$ there is a concern that because the composite arterial graft exhibits a single blood source, it might not supply sufficient blood flow to a wider area of myocardium. ${ }^{8,9}$ 




Myocardial single photon emission computed tomography (SPECT) has consistently been shown to be an effective modality for identifying myocardial viability and guiding appropriate management. Reversible perfusion decrease observed by means of myocardial SPECT is regarded as representing the viable ischemic myocardium, and the coronary territory in which the reversible perfusion decrease is seen is a primary target for a revascularization procedure. ${ }^{10}$

The aims of this study included (1) evaluation of late myocardial perfusion improvement after off-pump coronary artery bypass (OPCAB) using bilateral ITAs and (2) comparison of the degree and time course of myocardial perfusion improvement between the Y-composite and bilateral in situ ITAs based on the reversibility score of myocardial SPECT performed preoperatively and at 3 months and 1 year after OPCAB.

\section{Patients and Methods \\ Patient Selection}

Of 400 patients who underwent OPCAB between January 2000 and December 2002, 76 patients who underwent preoperative, 3-month, and 1-year myocardial SPECT testing were studied retrospectively. Myocardial SPECT was performed as a part of rou- tine clinical follow-up, and postoperative 1-year angiography (12 \pm 1 months postoperatively) was performed regardless of the patient's anginal symptoms. Inclusion criteria included (1) patients who underwent myocardial revascularization during OPCAB, (2) patients who received bilateral skeletonized ITAs as either a Ycomposite graft or in situ grafts for complete revascularization of the left coronary territory, (3) patients whose graft patency was confirmed by means of coronary angiography performed 1 year postoperatively, and (4) patients in whom both the resting and stress myocardial SPECT were performed preoperatively and 3 months and 1 year after OPCAB. Patients who received other arterial grafts or free grafts anastomosed on the ascending aorta to revascularize the left coronary territory or patients who did not receive the stress myocardial SPECT preoperatively because of intractable resting angina or an urgent or emergency situation were excluded from this study. Bilateral ITAs were used as a Ycomposite graft (group Y) in 39 patients and as in situ grafts in 37 patients (group I).

All patients halted aspirin therapy $(300 \mathrm{mg} / \mathrm{d})$ the day before the operation and resumed it 1 day postoperatively. Postoperative 1-year follow-up coronary angiography was performed in all the study patients, and all of the grafts were confirmed as patent. There were no differences between the 2 groups in terms of sex, age, preoperative risk factors (except hyperlipidemia), ratio of unstable to stable angina, left ventricular ejection fraction measured by means of transthoracic echocardiography, and angiographic diagnosis (Table 1). The study protocol was reviewed by the institutional review board and approved as a minimal risk retrospective study (approval no. H-0512-528-165) that did not require individual consent based on the institutional guidelines for waiving consent.

Operative Techniques and Revascularization Strategies OPCAB with skeletonized bilateral ITAs was performed as previously described. ${ }^{11}$ The patients were heparinized with an initial

Table 1. Preoperative characteristics and risk factors of study patients

\begin{tabular}{|c|c|c|c|}
\hline & Group Y (n = 39) & Group I ( $n=37)$ & $P$ value \\
\hline Sex (male/female) & $30 / 9$ & $31 / 6$ & .568 \\
\hline Age (y) & $61.9 \pm 7.0$ & $60.3 \pm 9.3$ & .390 \\
\hline LVEF $(\%)$ & $59.2 \pm 10.8$ & $55.6 \pm 10.1$ & .152 \\
\hline Unstable/stable & $30 / 9$ & $25 / 12$ & .445 \\
\hline \multicolumn{4}{|l|}{ Risk factors, $\mathrm{n}(\%)$} \\
\hline Smoking & $15(38.5)$ & $15(40.5)$ & 1.000 \\
\hline Hypertension & $29(74.4)$ & $19(51.4)$ & .057 \\
\hline Diabetes mellitus & $16(41.0)$ & $16(43.2)$ & 1.000 \\
\hline Hyperlipidemia & $13(33.3)$ & $5(13.5)$ & .059 \\
\hline Chronic renal failure & $1(2.6)$ & $0(0)$ & 1.000 \\
\hline COPD & $1(2.6)$ & $0(0)$ & 1.000 \\
\hline History of stroke & $3(7.7)$ & $8(21.6)$ & .109 \\
\hline History of MI & $8(20.5)$ & $7(18.9)$ & 1.000 \\
\hline \multicolumn{4}{|l|}{ Angiographic diagnosis, $\mathrm{n}(\%)$} \\
\hline Three-vessel disease & $34(87.2)$ & $28(75.7)$ & .244 \\
\hline $\begin{array}{l}\text { Left main disease with or } \\
\text { without peripheral disease }\end{array}$ & $9(23.1)$ & $12(32.4)$ & .445 \\
\hline
\end{tabular}

$\angle V E F$, Left ventricular ejection fraction; COPD, chronic obstructive pulmonary disease; $M I$, myocardial infarction. 
dose of $1.5 \mathrm{mg} / \mathrm{kg}$ heparin and periodically received supplemental doses to maintain an activated clotting time of longer than 300 seconds during OPCAB. Bilateral ITAs were preferred for use as in situ grafts for revascularization of the left coronary territory based on the assumption that 2 blood sources would provide a better long-term outcome than a single blood source. The right ITA was commonly used to revascularize the left anterior descending coronary artery by crossing the midline. It was also used occasionally to revascularize the ramus or high obtuse marginal branch through the transverse sinus as an in situ graft. If the right ITA was too short to reach the left coronary territory or if the left coronary territory could not be completely revascularized with bilateral in situ ITA grafts, a Y-composite graft was constructed before starting the distal anastomoses. In most instances of Y-composite graft construction, the right ITA was divided at its proximal section and was anastomosed in a Y fashion to the side of the left ITA with an 8-0 polypropylene continuous suture. A sequential anastomosing technique was used for additional revascularization in both groups. The right coronary artery territory was revascularized with either right gastroepiploic artery, radial artery, or saphenous vein grafts. Bypass grafting was indicated when the degree of native coronary stenosis was greater than $75 \%$. Protamine was not given at the end of the procedure. The operations were all performed by a single surgeon (K.-B.K.).

\section{Myocardial SPECT Testing}

Thallium-201 rest/dipyridamole stress technetium-99m methoxyisobutylisonitrile (MIBI)-gated SPECT was performed. Thallium201 (111 MBq) was injected at rest, and SPECT was performed. Dipyridamole $(0.56 \mathrm{mg} / \mathrm{kg})$ was then injected for more than 4 minutes to induce stress for assessment of the coronary perfusion reserve, and technetium-99m (925 MBq) was injected 3 minutes after stress. Gated technetium-99m-MIBI SPECT was performed 90 minutes after stress by using a dual-head camera equipped with a low-energy, high-resolution collimator (Vertex EPIC; ADAC Laboratories, Malpitas, Calif). Thallium-201 rest/dipyridamole stress technetium-99m-MIBI-gated SPECT was repeated 3 months $(102 \pm 20$ days $)$ and 1 year $(15 \pm 2$ months $)$ after OPCAB as a follow-up examination by using the same protocol as was used for the preoperative study. A 20-segment model was adopted for regional analysis. Each segment was subtended to 2 coronary arterial territories (right and left coronary territories), and all of the 16 segments representing the left coronary territory (left anterior descending artery and left circumflex artery territories) were analyzed as a whole (Figure 1). The segments representing the right coronary artery territory were excluded.

\section{Quantification of Myocardial Regional Perfusion}

After overall image quality was assessed by 2 experts, the reconstructed images were analyzed with an automatic quantifying software package (AutoQUANT, ADAC Laboratories) without manual intervention. Resting and stress segmental myocardial perfusion was quantified by measuring radioactivity and expressed as the percentage of the maximal radioactivity uptake. As an indicator of the reversibility of perfusion impairment, the reversibility score (presented as a percentage) was defined as a measure of rest minus stress perfusion values in each segment. The reversible myocardial segments of the left coronary territory were se-

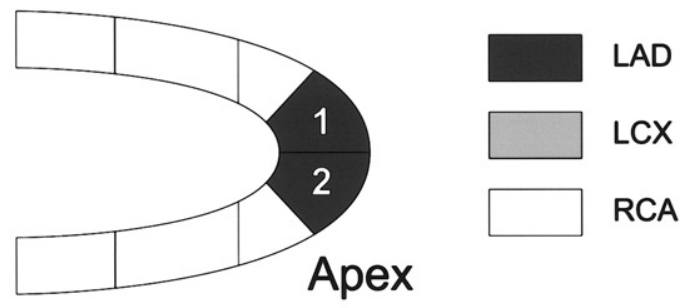

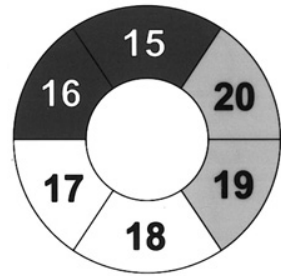

Basal

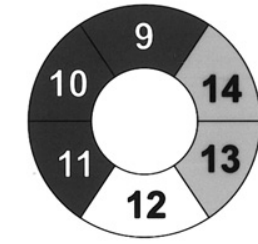

Mid

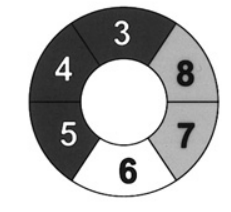

Apical

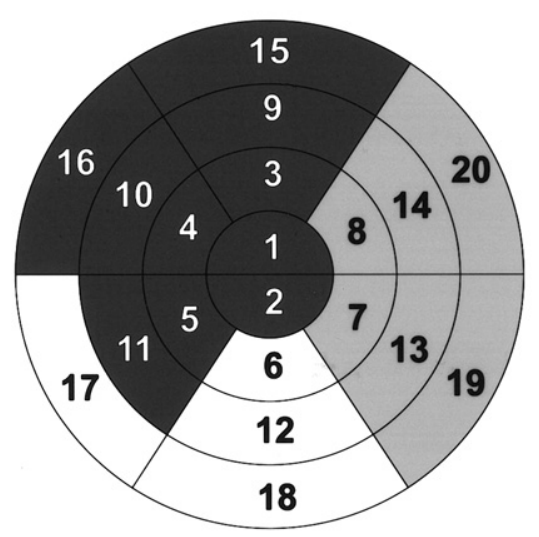

Figure 1. Selection of $\mathbf{1 6}$ segments for segmental analysis in a 20-segment model. $L A D$, Left anterior descending coronary artery; LCX, left circumflex coronary artery; $R C A$, right coronary artery.

lected based on a cutoff value of 7, suggesting a viable segment in terms of perfusion reversibility. ${ }^{3}$ A total of 403 segments (227 segments in group Y; 176 segments in group I) that showed a reversibility score of 7 or greater preoperatively were included in the analysis.

\section{Statistical Analysis}

Statistical analysis was performed with SPSS 11.0 software (SPSS, Inc, Chicago, Ill). Statistical analysis comparing the data was performed with paired and unpaired Student $t$ tests and MannWhitney $U$ tests. The discrete variables were analyzed by using the $\chi^{2}$ and Fisher exact tests. Repeated-measures analysis of variance was used to compare the difference of time sequence of myocardial reversibility scores between the 2 groups. This was followed by the paired Student $t$ test to analyze the change of reversibility scores within each group. All results were expressed as means \pm standard deviation. 
Table 2. Segmental myocardial perfusion value

\begin{tabular}{|c|c|c|c|c|c|c|}
\hline Group & Variables & Preoperative & Postoperative 3 mo & Postoperative $1 \mathrm{y}$ & $P$ value* & $P$ valuet \\
\hline \multirow[t]{3}{*}{ Total ( $\mathrm{n}=76 ; 403$ segments) } & Resting (\%) & $74.7 \pm 13.4$ & $74.3 \pm 12.8$ & $70.5 \pm 13.6$ & & \\
\hline & Stress $(\%)$ & $59.2 \pm 14.8$ & $69.8 \pm 14.5$ & $70.9 \pm 13.2$ & & \\
\hline & Reversibility score (\%) & $15.5 \pm 9.0$ & $4.5 \pm 7.4$ & $-0.4 \pm 7.7$ & $<.001$ & $<.001$ \\
\hline \multirow[t]{3}{*}{ Group Y ( $\mathrm{n}=39 ; 227$ segments) } & Resting (\%) & $77.0 \pm 13.2$ & $73.9 \pm 13.7$ & $69.9 \pm 13.7$ & & \\
\hline & Stress $(\%)$ & $62.2 \pm 14.0$ & $69.6 \pm 15.8$ & $71.6 \pm 13.6$ & & \\
\hline & Reversibility score (\%) & $14.8 \pm 8.1$ & $4.3 \pm 7.3$ & $-1.7 \pm 7.9$ & $<.001$ & $<.001$ \\
\hline \multirow[t]{3}{*}{ Group I (n = 37;176 segments) } & Resting $(\%)$ & $71.6 \pm 13.1$ & $74.9 \pm 11.5$ & $71.3 \pm 13.4$ & & \\
\hline & Stress $(\%)$ & $55.3 \pm 14.8$ & $70.1 \pm 12.6$ & $70.1 \pm 12.7$ & & \\
\hline & Reversibility score (\%) & $16.3 \pm 10.0$ & $4.8 \pm 7.6$ & $1.3 \pm 7.2$ & $<.001$ & $<.001$ \\
\hline
\end{tabular}

$* P$ value between the preoperative period and 3 months after the operation. $\dagger P$ value between 3 months and 1 year after the operation.

\section{Results}

\section{Operative Results}

The average numbers of distal anastomoses per patient and per bilateral ITA were $3.2 \pm 0.8$ and $2.6 \pm 0.7$, respectively. The average number of distal anastomoses per bilateral ITA was larger in group Y than in group I $(2.8 \pm 0.8$ vs $2.4 \pm 0.5, P=.008$ ), although there was no significant difference regarding the average number of distal anastomoses per patient between the 2 groups ( $3.4 \pm 0.9$ in group Y vs $3.1 \pm 0.7$ in group I, $P=.061$ ). A larger number of patients in group $\mathrm{Y}$ required sequential anastomoses than in group I (59.0\% [23/39] vs 32.4\% [12/37], $P=.024)$. There were no significant differences regarding the incidence of postoperative morbidities, such as atrial fibrillation (17.9\% [7/39] vs $24.3 \%$ [9/37], $P=.597)$, perioperative myocardial infarction ( $0 \%$ vs $5.4 \%$ [2/37], $P=.234)$, acute renal failure (0\% vs $2.7 \%$ [1/37], $P=.487$ ), and reoperation for bleeding (5.1\% [2/39] vs $2.7 \%$ [1/37], $P=1.000)$, between groups $\mathrm{Y}$ and I. We did not experience any low cardiac output syndrome, mediastinitis, or stroke in either group.

\section{Myocardial SPECT Test}

The mean values of preoperative, postoperative 3-month, and postoperative 1-year segmental perfusion in the resting SPECT were $74.7 \% \pm 13.4 \%, 74.3 \% \pm 12.8 \%$, and $70.5 \%$ $\pm 13.6 \%$, and those in the stress SPECT were $59.2 \% \pm$ $14.8 \%, 69.8 \% \pm 14.5 \%$, and $70.9 \% \pm 13.2 \%$, respectively. The reversibility scores were improved significantly at postoperative month 3 and further improved 1 year after the operation when compared with the preoperative values $(15.5 \% \pm 9.0 \%$ vs $4.5 \% \pm 7.4 \%$ vs $-0.4 \% \pm 7.7 \%, P<$ .001) (Table 2). When the patients were divided into 2 groups based on the type of bilateral ITA used (group Y, Y-composite graft; group I, bilateral in situ grafts), the reversibility scores were significantly improved at postoperative month 3 and at 1 year in both groups when compared with the preoperative values (group Y: $14.8 \% \pm 8.1 \%$ vs $4.3 \% \pm 7.3 \%$ vs $-1.7 \% \pm 7.9 \%, P<.001$; group I: $16.3 \%$ $\pm 10.0 \%$ vs $4.8 \% \pm 7.6 \%$ vs $1.3 \% \pm 7.2 \%, P<.001)$.
There were no significant differences in the reversibility scores between groups $\mathrm{Y}$ and $\mathrm{I}$ at postoperative month 3 ( $P$ $=.463)$. The scores approached zero in both groups at 1 year postoperatively, suggesting almost complete recovery of myocardial stress perfusion by the first postoperative year (Table 3).

\section{Discussion}

This study demonstrated 2 main findings. First, the myocardial reversibility score improved progressively until 1 year after OPCAB by using bilateral ITAs. Second, revascularization with a Y-composite or bilateral in situ ITA graft exhibited a similar pattern of reversibility improvement until 1 year postoperatively.

The salutary effect of coronary artery bypass grafting has been demonstrated as a progressive improvement of myocardial blood flow, myocardial function, and flow reserve of the arterial conduit after successful revascularization. ${ }^{1-3,12,13}$ Myocardial blood flow and coronary vasodilator reserve have been shown to increase gradually after myocardial revascularization, and microvascular dysfunction after surgical intervention has been suggested as a cause of the slow recovery. ${ }^{2}$ The recovery of regional and global left ventricular function after myocardial revascularization has also been reported by Vanoverschelde and associates ${ }^{1}$ to be progressive and followed a monoexponential time course with a median time constant of 23 days when measured by means of two-dimensional echocardiography. The temporal variations in functional recovery have been

Table 3. Comparison of the reversibility scores between the 2 groups

\begin{tabular}{lrcc}
\hline Variables & \multicolumn{1}{c}{ Group Y } & Group I & P value \\
\hline Preoperative (\%) & $14.8 \pm 8.1$ & $16.3 \pm 10.0$ & .089 \\
Postoperative, 3 mo (\%) & $4.3 \pm 7.3$ & $4.8 \pm 7.6$ & .463 \\
Postoperative, 1 y (\%) & $-1.7 \pm 7.9$ & $1.3 \pm 7.2$ & $<.001^{*}$
\end{tabular}

*Approaching zero value, suggesting complete recovery of stress perfusion in both groups. 
suggested to be related to the pathophysiologic mechanism of myocardial dysfunction, where stunned myocardium exhibits earlier functional recovery than hibernating myocardium., ${ }^{3,14}$ The increase in myocardial blood flow has been shown to result in vasodilatation and increased flow reserve of ITA grafts in the late postoperative period. ${ }^{13,15}$ Those previous studies, however, were performed without confirmation of late graft patency.

Despite advances in cardiopulmonary bypass and myocardial protection, the reduced myocardial flow reserve in the early postoperative period has been attributed to the use of cardiopulmonary bypass. ${ }^{13}$ The present study included those patients who underwent OPCAB and whose 1-year patency of all grafts was confirmed by using postoperative coronary angiography. We performed myocardial SPECT at both 3 months, when ischemic myocardial dysfunction would be expected to have recovered from ischemia after revascularization, ${ }^{1}$ and 1 year after surgical intervention. In the previous study ${ }^{12}$ the difference with regard to stress perfusion between preoperative and postoperative SPECT was compared to evaluate the postoperative improvement of myocardial stress perfusion. The difference in stress perfusion was calculated and compared because there was a baseline difference in stress perfusion between the 2 groups. In the present study the reversibility score (presented as a percentage) was calculated by subtracting the stress perfusion value from the resting perfusion value, and a cutoff value of 7 was adopted to study the viable myocardial segments based on previous studies. ${ }^{3,16}$ The present study demonstrated that the myocardial reversibility score significantly improved at 3 months postoperatively and further improved at 1 year postoperatively, suggesting progressive improvement of myocardial perfusion until 1 year after OPCAB.

Enhanced long-term survival rates and greater freedom from reintervention have been indicated when bilateral ITAs are used rather than a single ITA graft in patients exhibiting multivessel disease. ${ }^{4,5}$ The skeletonized technique for harvesting the ITA has been shown to provide additional length, superior free flow, and easier use of ITAs as grafts, with favorable results. ${ }^{11,17,18}$ Those results have provided the foundation for using bilateral ITA grafts to achieve complete myocardial revascularization. In spite of the extra graft length obtained by using the skeletonization technique, the length of the right ITA is the main limitation for bilateral in situ ITA grafting. Construction of a composite graft, such as a Y or T graft, increases the length of the ITA and allows the extensive use of bilateral ITA grafts to revascularize both the left and right coronary systems. ${ }^{19}$ Although several studies have shown that a composite graft increases coronary flow reserve and has a favorable outcome, ${ }^{6,19,20}$ there is a concern that it might not supply sufficient blood flow to a wider area of myocardium because the composite arterial graft only provides a single blood source. ${ }^{9,21}$

The present study analyzed patients who underwent OPCAB with skeletonized ITAs used to revascularize the left coronary artery territory. When the patients were divided into 2 groups based on the bilateral ITAs used, Y-composite (group Y) or in situ grafts (group I), the reversibility score was significantly improved at postoperative month 3 and year 1 in both groups when compared with the preoperative values. When the mean values of reversibility score were compared between groups Y and I, there were no significant differences preoperatively $(14.8 \% \pm$ $8.1 \%$ vs $16.3 \% \pm 10.0 \%, P=.089)$ and at postoperative month $3(4.3 \% \pm 7.3 \%$ vs $4.8 \% \pm 7.6 \%, P=.463)$, respectively. The insignificant differences in reversibility scores between the 2 surgical techniques document the dynamics and flow reserve of the ITA graft and attenuate the existing concerns of limited flow reserve of the composite arterial graft for multiple distal anastomoses.

Those scores approached zero (group Y, $-1.7 \% \pm 7.9 \%$ vs group I, $1.3 \% \pm 7.2 \%$ ), suggesting almost complete recovery of myocardial stress perfusion by the first postoperative year. When the reversibility scores were compared within each group, the scores progressively decreased until 1 year in both groups. Because the time-dependent progression of improved perfusion suggested a gradual adaptation of flow reserve in both Y-composite and in situ ITA grafts, revascularization with either a Y-composite or bilateral in situ graft might be sufficient for revascularization of the left coronary territory.

There are limitations to the present study that must be recognized. First, the present study was not performed in a randomized manner because randomized controlled trials with regard to this type of study are often unrealistic and impractical. There were some baseline differences between the 2 groups. The average number of distal anastomoses per bilateral ITA was smaller in group I than in group Y, although there was no significant difference regarding the average number of distal anastomoses per patient between the 2 groups. Although the study involved a relatively small number of patients and was not randomized, this study collected all institutional experience by using a computerbased database system. Second, a 20 -segment model was adopted for regional analysis, and all of the 16 segments representing the left coronary territory were analyzed as a whole. We analyzed the 16 segments without consideration of the coronary artery dominance pattern of each patient. Third, coronary angiography was performed to confirm the graft patency $12 \pm 1$ months postoperatively, and the 1-year myocardial SPECT was performed $15 \pm 2$ months after OPCAB. Some grafts might have occluded during the 3-month interval period, which would affect the results of myocardial SPECT. 


\section{References}

1. Vanoverschelde J-LJ, Depré C, Gerber BL, Borgers M, Wijns W, Robert A, et al. Time course of functional recovery after coronary artery bypass graft surgery in patients with chronic left ventricular ischemic dysfunction. Am J Cardiol. 2000;85:1432-9.

2. Spyrou N, Khan MA, Rosen SD, Foale R, Davies DW, Sogliani F, et al. Persistent but reversible coronary microvascular dysfunction after bypass grafting. Am J Physiol Heart Circ Physiol. 2000;279:H263440.

3. Paeng JC, Lee DS, Kang WJ, Lee BI, Kim K-B, Chung J-K, et al. Time course of functional recovery after coronary artery bypass grafting surgery according to the preoperative reversibility of perfusion impairment on myocardial SPECT. Eur J Nucl Med Mol Imaging. 2005;32:70-4

4. Buxton BF, Komeda M, Fuller JA, Gordon I. Bilateral internal thoracic artery grafting may improve outcome of coronary artery surgery; risk-adjusted survival. Circulation. 1998;98:II1-6.

5. Lytle BW, Blackstone EH, Loop FD, Houghtaling PL, Arnold JH, Akhrass R, et al. Two internal thoracic artery grafts are better than one. J Thorac Cardiovasc Surg. 1999;117:855-72.

6. Wendler O, Hennen B, Markwirth T, König J, Tscholl D, Huang Q, et al. $\mathrm{T}$ grafts with the right internal thoracic artery to left internal thoracic artery versus the left internal thoracic artery and radial artery: flow dynamics in the internal thoracic artery main stem. $J$ Thorac Cardiovasc Surg. 1999;118:841-8.

7. Royse AG, Royse CF, Groves KL, Bus B, Yu G. Blood flow in composite arterial grafts and effect of native coronary flows. Ann Thorac Surg. 1999;68:1619-22.

8. Ochi M, Hatori N, Bessho R, Fujii M, Saji Y, Tanaka S, et al. Adequacy of flow capacity of bilateral internal thoracic artery $\mathrm{T}$ graft. Ann Thorac Surg. 2001;72:2008-12.

9. Lev-Ran O, Paz Y, Pevni D, Kramer A, Shapira I, Locker C, et al. Bilateral internal thoracic artery grafting: Midterm results of composite versus in situ crossover graft. Ann Thorac Surg. 2002;74:704-11.

10. Travin MI, Bergmann SR. Assessment of myocardial viability. Semin Nucl Med. 2005;35:2-16.

11. Kim K-B, Cho KR, Chang W-I, Lim C, Ham BM, Kim YL. Bilateral skeletonized internal thoracic artery graftings in off-pump coronary artery bypass: early result of Y versus in situ grafts. Ann Thorac Surg. 2002;74(suppl):1371-6.

12. Kang CH, Kim K-B, Park CS, Paeng JC, Lee DS. Improvement of myocardial stress perfusion after off-pump revascularization using bilateral internal thoracic in situ grafts versus Y-composite grafts. Ann Thorac Surg. 2005;79:93-8.

13. Gurné O, Chenu P, Polidori C, Louagie Y, Buche M, Haxhe JP, et al. Functional evaluation on internal mammary artery bypass grafts in the early and late postoperative periods. J Am Coll Cardiol. 1995;25: 1120-8.

14. Haas F, Jennen L, Heinzmann U, Augustin N, Wottke M, Schwaiger $\mathrm{M}$, et al. Ischemically compromised myocardium displays different time-courses of functional recovery: correlation with morphological alterations? Eur J Cardiothorac Surg. 2001;20:290-8.

15. Akasaka T, Yoshikawa J, Yoshida K, Maeda K, Hozumi T, Nasu M, et al. Flow capacity of internal mammary artery grafts: early restriction and later improvement assessed by Doppler guide wire; comparison with saphenous vein grafts. J Am Coll Cardiol. 1995;25:640-7.

16. Kang WJ, Lee DS, Paeng JC, Kim K-B, Chung J-K, Lee MC. Prognostic value of rest $201 \mathrm{Tl}$-stress dipyridamole-99mTc-Sestamibi gated SPECT for predicting patient-based clinical outcomes after bypass surgery in patients with ischemic left ventricular dysfunction. $J$ Nucl Med. 2003;44:1735-40.

17. Kramer A, Mastasa M, Paz Y, Locker C, Pevni D, Gurevitch J, et al. Bilateral skeletonized internal thoracic artery grafting in 303 patients seventy years and older. J Thorac Cardiovasc Surg. 2000;120:290-7.

18. Takami Y, Hiroshi I. Effects of skeletonization on intraoperative flow and anastomosis diameter of internal thoracic arteries in coronary artery bypass grafting. Ann Thorac Surg. 2002;73:1441-5.

19. Calafiore AM, Contini M, Vitolla G, Di Mauro M, Mazzei V, Teodori $\mathrm{G}$, et al. Bilateral internal thoracic artery grafting: long-term clinical and angiographic results of in situ versus Y grafts. J Thorac Cardiovasc Surg. 2000;120:990-8.

20. Tector AJ, McDonald ML, Kress DC, Dawney FX, Schmahl TM. Purely internal thoracic arterial grafts: outcomes. Ann Thorac Surg. 2001;72:450-5.

21. Sakaguchi G, Tadamura E, Ohnaka M, Tambara K, Nishimura K, Komeda M. Composite arterial Y graft has less coronary flow reserve than independent grafts. Ann Thorac Surg. 2002;74:493-6. 